\title{
ASSESSMENT OF TRENDS AND VARIABILITY OF RAINFALL AND TEMPERATURE FOR THE DISTRICT OF MANDI IN HIMACHAL PRADESH, INDIA
}

\author{
John MOHD WANI ${ }^{1}$, V. K. SARDA*2, Sanjay. K. JAIN²
}

\begin{abstract}
Climate variability, particularly, that of the annual air temperature and precipitation, has received a great deal of attention worldwide. The magnitude of the variability of the factors changes according to the locations. The present study focuses on detecting the trends and variability in the annual temperature and rainfall for the district of Mandi in Himachal Pradesh, India. This study used annual and monsoon time series data for the time period 1981-2010 and modified the Mann-Kendall test and Sen's slope estimator in analyzing the problem. The results of the analysis indicate that the annual maximum temperature (TMX) and annual minimum temperature (TMN) for the period of 30 years have shown an increasing trend, whereas the monsoon's maximum and minimum temperatures have shown a decreasing trend, although it is statistically not significant. The amount of annual rainfall does not show any significant trend, but the monsoonal rainfall has shown an increasing trend that is also statistically not significant. The resulting Mann-Kendall test statistic (Z) and Sen's slope estimate (Q) of all the parameters studied indicate that changes are occurring in the magnitude and timing of the precipitation and temperature events at the Mandi station.
\end{abstract}

\section{Address}

1 Department of Civil Engineering, NIT Hamirpur, Himachal Pradesh, India,

2 National Institute of Hydrology, Roorkee, Uttrakhand, India, email: sanjay.nih@gmail.com

\section{* Corresponding author: sardavk@yahoo.com}

\section{Key words}

- Climate change,

- Mann-Kendall,

- Precipitation,

- Sens's Slope Estimator,

- Temperature,

- Trend analysis.

\section{INTRODUCTION}

Global climate change may influence long-term rainfall patterns, which affect the availability of water, along with the risk of increasing droughts and floods. According to the Intergovernmental Panel on Climate Change (IPCC), the global temperature has increased by $0.74^{\circ} \mathrm{C} \pm$ $0.18^{\circ} \mathrm{C}$ over the last 100 years (1905-2005), and precipitation is likely to increase by 0.2 to $0.3 \%$ per decade over tropical land areas in the $21^{\text {st }}$ century (IPCC, 2007). It is also recognized that rainfall and temperature are among the most important climatic variables that involve both spatial and temporal patterns of water availability. Taking the Himalayan region into consideration, the variability and trends in temperature are among the most significant aspects of climate change studies. The im- pact of climate change on the Himalayan ranges affects the snow cover and river flow over the northwestern Himalayas. It is also a well-known fact that longterm alterations in temperature have a significant impact on the hydrological cycle. Disturbances in the hydrological cycle may bring about changes in rainfall patterns, extreme precipitation events and drought conditions, which in turn affect the hydrological, agricultural and economic planning of the country. Understanding trends and variability of climatic factors is essential for appreciating the impact of climate change. It is therefore becoming clearer that analyses of rainfall and temperature trends are important when considering the impact of climate change on water resources planning and management.

The purpose of this study is to investigate the variability of the rainfall and temperature of the district of Mandi in the state of Hi- 
machal Pradesh in India. This includes an understanding of the area's rainfall and temperature trends or changes. Understanding the uncertainties associated with precipitation and temperature patterns will provide a knowledge base for better management of agriculture, irrigation, hydropower generation, and other water-related activities in the selected area.

\section{LITERATURE REVIEW}

The trends in climate change provide a general idea of any changes noticeable within the historical data and point out certain concerns for the area regarding extreme events. Studies related to changes in rainfall over India have concluded that there is no clear trend in the average annual rainfall over the country (Jain and Kumar, 2012). The extreme precipitation indices are becoming more extreme, which could be partially attributed to recent warming in the Himalayan region (Sharif et al. 2010). An analysis of the trends in the northern part of India clearly shows that precipitation patterns are undergoing significant changes, probably under the impacts of climate change (Sharif et al. 2013).

Several precipitation trend studies have also been carried out in the south Asia region. (Marco et al. 2003) showed that there is an increasing precipitation trend throughout the year southwest of Xinjiang, which is an area adjacent to the northern part of Pakistan, and in Jammu- Kashmir, which is southwest of Tibet (Hussain et al. 2012). Heavy rainfall in the summer season over coastal areas of India shows an increasing trend and has been attributed to the possible impacts of climate change (Roy et al. 2005). The frequency of heavy rainfall events is decreasing in major parts of central and northern India, while they are increasing in peninsular, east and northeast India (Guhathakurta et al. 2011). A study of the temperature data (19611999) of 7 climate stations in the Karakoram and Hindu Kush mountains using statistical regression techniques revealed winter warming and summer cooling trends (Fowler and Archer, 2006). Several recent studies have revealed that the South Asia region is significantly warming and that the warming tendency is largely consistent with global warming trends (Singh et al. 2008). A study of long-term mean annual temperatures from 1901 to 1982 over India identified an increasing trend in mean surface air temperatures (Hingane et al. 1985). An analysis of extreme flow measures in the Sutlej River basin in India revealed decreasing trends in high flow magnitudes, but no statistically significant trend was observed in low flow events (Sharif et al. 2010).

The safety of water in the northern part of India is likely to be impacted owing to changes in the temporal and spatial distribution of water due to possible climate change effects. The utmost and direct effects of global warming would be on changes in the local and regional availability of water (Jiang et al. 2007). Recent droughts in northern India and unprecedented floods in parts of Southern India are seen as an indicator of current climate changes, and changes in the patterns of the monsoon in the northern parts affect the country's agriculture since India is an agriculture-dependent economy, and monsoons are the lifeline of the agriculture sector (Sharif et al. 2013). Several studies have reported that warming has taken place all over India (Singh et al. 2008).

For a trend analysis, non-parametric tests are widely used compared to their parametric counterparts. When comparing their strength, i.e., their ability to distinguish between the null hypothesis and an alternative hypothesis, the Mann-Kendall (M-K) tests (Mann 1945; Kendall 1975) for monotonic trends give better results in comparison to the parametric $t$ - test (Van Belle \& Hughes, 1984). Non-parametric methods have been found to be suitable for data commonly skewed, and the sample size is large (Hirsch et al. 1982). Parametric trend tests are more powerful than non-parametric ones, but they require data to be independent and normally distributed (Chen et al. 2007). The main advantage of the Mann-Kendall test is that it is free from the assumption of the normality of the data and can tolerate outliers in the data series (Hamid et al, 2013). The M-K test has been approved as a powerful tool to detect trends in hydro-meteorological time series (Chen et al. 2007). Nonparametric tests have various advantages over parametric ones. Some of these are as follows: (a) prior transformations are not required, even when approximate normality could be achieved; (b) an assumption of normality or the assumption of the homogeneity of a variance is not required; (c) greater power is achieved for skewed distributions; (d) comparisons are made between central values such as the median, rather than the mean; as a result, if the data have one or two outliers, their influence is negated; and, finally, (e) data below the detection limit can be incorporated without any fabrication of the values or bias (Helsel, 1987; Duhan and Pandey 2013).

Many researchers have tried to determine trends in rainfall on both land and regional scales. Most of these studies deal with an analysis of the annual and seasonal series of rainfall for some individual stations or groups of stations. In this study, we have investigated the variability of rainfall and temperature on a local scale at the Mandi station in Himachal Pradesh, India.

\section{MATERIAL AND METHODS}

\subsection{Study Area}

Mandi is located at the $31^{\circ} 72^{\prime} \mathrm{N}$ latitude and $76^{\circ} 92^{\prime} \mathrm{E}$ longitude (Figure: 1) and covers a geographical area of $3951 \mathrm{~km}^{2}$. The city is located on the banks of the Beas River, at the confluence of the Suketi Khad stream in Himachal Pradesh. Sikandar Dhar, Ghugar Dhar, and Dhar Kot are some of the prominent hills and mountains found near the city. It lies in the midlands of the Himalayan range. It has a complex terrain with elevations ranging from 450 to $4800 \mathrm{~m}$.

The climate of the district ranges from wet sub-temperate to a dry, cold, alpine climate with snowfalls at higher altitudes, depending upon the elevation. The major seasons are: the winter season, which extends from November to February; the summer season from March to June; the monsoon period extending from July to the end of September. The maximum rainfall occurs from July to September. The average annual rainfall in the Mandi station is about $832 \mathrm{~mm}$. In the non-monsoon season, precipitation in the form of snowfall also occurs in the higher reaches above elevations of 2400 to $4800 \mathrm{~m}$. The average temperature during the summer is between $18.9^{\circ} \mathrm{C}$ and 39.6 ${ }^{\circ} \mathrm{C}$ and varies between $6.7^{\circ} \mathrm{C}$ and $26.2^{\circ} \mathrm{C}$ in the winter.

\subsection{Data used}

Daily Climate Forecast System Reanalysis (CFSR) data was used due to the limited availability of data; it was procured from the global weather data for SWAT (https://globalweather.tamu.edu/), which was only available for the time period of 1981-2010. Some missing values were filled in using interpolations between the previous and the next day's data. The data was checked for any discrepancies before it was used. The distribution of monthly rainfall for the Mandi station is shown in Figure 2. It reveals that the maximum rainfall in the area occurs during the monsoon period (June to September). During the winter season (December, January and February) only a small amount of rainfall occurs. The distribution of the monthly maximum temperatures is shown in Figure 3 and reveals that May and June are the 


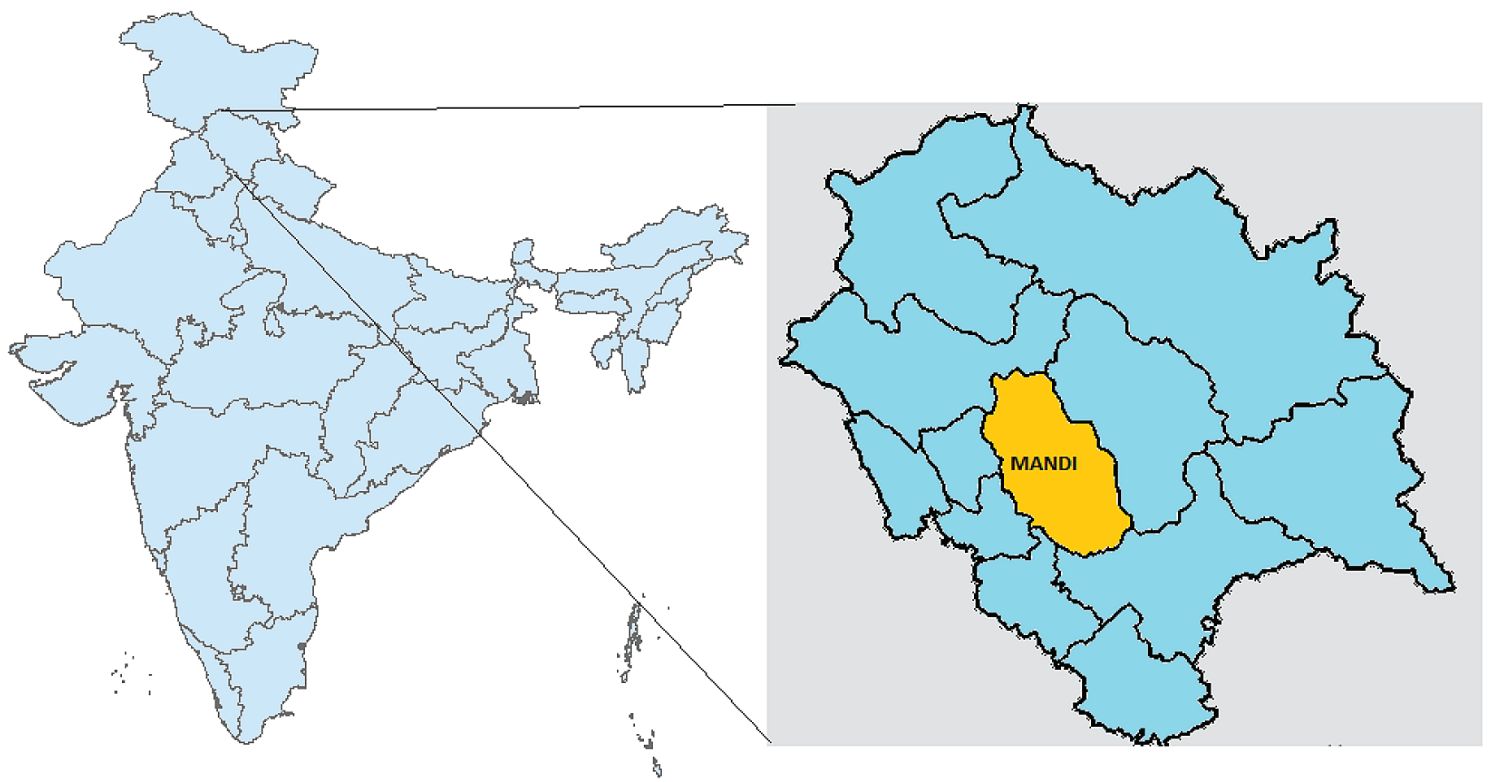

Fig. 4 Comparison of the required reinforcement area according to the NDP in NA of EN 1992-1-1 and Model Code 2010 (Sonnenschein et al., 2016)

hottest months in the area. The distribution of the monthly minimum temperature is shown in Figure 4.

\section{METHODOLOGY}

\subsection{Mann-Kendall test}

The Mann-Kendall (M-K) test is a statistical test widely used for trend analysis in climatological and hydrological time series. There are two advantages to using this test. First, it is a non-parametric test and does not require the data to be normally distributed. Second, the test has low sensitivity to abrupt breaks due to inhomogeneous time series. Any data reported as "non-detects" are included by assigning them a common value that is smaller than the smallest measured value in the data set. According to this test, the null hypothesis $\mathrm{H} 0$ assumes that there is no trend (the data is independent and randomly ordered). This is tested against the alternative hypothesis $H_{1}$, which assumes that there is a trend.

The Mann-Kendall statistic is computed as follows:

$$
S=\sum_{k=1}^{n-1} \sum_{j=k+1}^{n} \operatorname{sgn}\left(x_{j}-x_{k}\right)
$$

The trend test is applied to a time series $x_{k}$, which is ranked from $k=1,2,3, \ldots n-1$ and $x$, which is ranked from $j=i+1, i+2, i+$ $+3, \ldots n$. Each of the data points $x_{j}$ is taken as a reference point, which is compared with the rest of the data points $x_{k}$, so that,

$$
\operatorname{sgn}\left(x_{j}-x_{k}\right)=\left[\begin{array}{l}
1 \text { if }\left(x_{j}-x_{k}\right)>0 \\
0 \text { if }\left(x_{j}-x_{k}\right)=0 \\
-1 \text { if }\left(x_{j}-x_{k}\right)<0
\end{array}\right]
$$

Here $x_{j}$ and $x_{k}$ are the sequential data values, and $n$ is the length of the data set. For samples greater than 10, the test is conducted using a normal distribution (Helsel et al. 1992) with the mean and variance as follows:

The variance $\sigma^{2}$ for the $\mathrm{S}$ statistic is defined by:
$E[S]=0$

$$
\operatorname{Var}(S)=\frac{1}{18}\left[n(n-1)(2 n+5)-\sum_{p=1}^{q} t_{p}\left(t_{p}-1\right)\left(2 t_{p}+5\right)\right]
$$

Here $t_{p}$ is the number of data points in the $p^{\text {th }}$ tied group, and $q$ is the number of tied groups in the data set.

The standardized test statistic $Z_{m, k}$ is calculated by:

$$
Z_{m k}=\left[\begin{array}{cc}
\frac{\mathrm{S}-1}{\sqrt{\operatorname{var}(S)}} & \text { if } \mathrm{S}>0 \\
\frac{\mathrm{S}+1}{\sqrt{\operatorname{var}(S)}} & \text { if } \mathrm{S}<0 \\
0 & \text { if } \mathrm{S}=0
\end{array}\right]
$$

where the value of $Z_{m k}$ is the Mann-Kendall test statistics that follow the standard normal distribution with a mean of zero and a variance of one. Thus, in a two-sided trend test, the null hypothesis $H_{0}$ is accepted if $-Z_{1-\alpha / 2} \leq \mathrm{Zmk} \leq \mathrm{Z}_{1-\alpha / 2}$, where $\alpha$ is the level of significance that indicates the trend's strength.

\subsection{Sen's Slope Estimator Test}

The magnitude of a trend in a time series can be determined using a non-parametric method known as Sen's estimator (Sen, 1968). To estimate the true slope of an existing trend such as the amount of change per year, Sen's nonparametric method is used. Sen's method can be used in cases where the trend can be assumed to be linear such as:

$$
f(t)=Q t+B
$$

Here $Q$ is the slope, and $B$ is a constant.

To get the slope estimate $Q$ in Eq. 7, the slopes of all the data value pairs are calculated as:

$$
Q_{i}=\frac{x_{j}-x_{k}}{j-k}
$$


Here $x_{j}$, and $x_{k}$ are the data values in years $j$ and $k, j>k$.

If there are $n$ values of $x_{j}$ in the time series, one gets as many as $N$ $=n(n-1) / 2$ slope estimates $Q_{i}$.

Sen's estimator of the slope is the median of these $N$ values of $Q_{i}$ The $N$ values of $Q_{i}$ are ranked from the smallest to the largest, and Sen's estimator is

$$
\begin{array}{ll}
Q=Q_{[(N+1) / 2]} & \text { if } N \text { is odd } \\
Q=\frac{1}{2}\left(Q_{[N / 2]}+Q_{[(N+1) / 2]}\right) & \text { if } \mathrm{N} \text { is even }
\end{array}
$$

A $100(1-\alpha) \%$ two-sided confidence interval about the slope estimate is obtained by the nonparametric technique based on the normal distribution. The method is valid for $n$ as small as 10 unless there are many ties. A positive value of $Q_{i}$ indicates an upward or increasing trend, and a negative value gives a downward or decreasing trend in the time series.

\section{RESULTS AND DISCUSSION}

\subsection{Analysis of Monthly Rainfall}

A variability analysis of hydro-meteorological parameters is of great importance for researchers in their decision-making. The compact nature of box and whisker plots (Tukey, 1977) assists side-by-side assessments of multiple datasets, which can otherwise be difficult to interpret using more complete representations, such as the histogram (Banacos, 2011). These plots graphically describe the statistical distribution in a way that is easy to understand for a wide range of users. The form of the box and whisker plot here include: a central horizontal line representing the median and the interquartile range's top and bottom horizontal lines (shown by the box). The bottom and top horizontal lines in the boxes indicate the $25^{\text {th }}$ and $75^{\text {th }}$ percentiles, respectively. The outer ranges are drawn as vertical lines (as shown by the whiskers).

The location of the median line can suggest skewness in the distribution if it is noticeably shifted away from the center. The length of the interquartile range (IQR) as shown by the box is a measure of the relative dispersion of the middle $50 \%$ of a dataset, just as the length of each whisker is a measure of the relative dispersion of the dataset's outer range ( $10^{\text {th }}$ to $25^{\text {th }}$ percentiles and $75^{\text {th }}$ to $90^{\text {th }}$ percentiles) (Banacos, 2011). Figure 2 presents the box plots of the monthly rainfalls observed at Mandi from 1981-2010. The total monthly rainfall was obtained by totaling the daily values of each month for each year. The plots show the relatively maximum amount of rainfall in July and August; since the length of the boxes and whiskers is longer, the variability is greater compared to the other months.

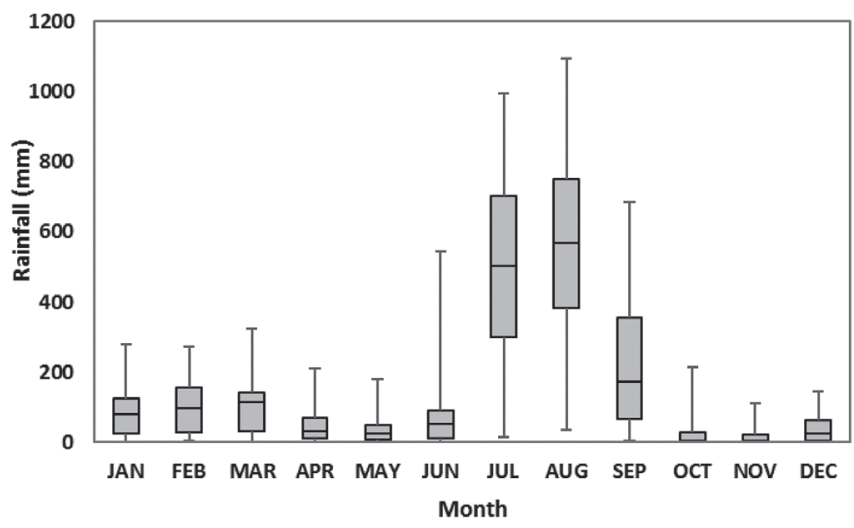

Fig. 2. Box and Whisker plot of monthly rainfall ( $\mathrm{mm})$

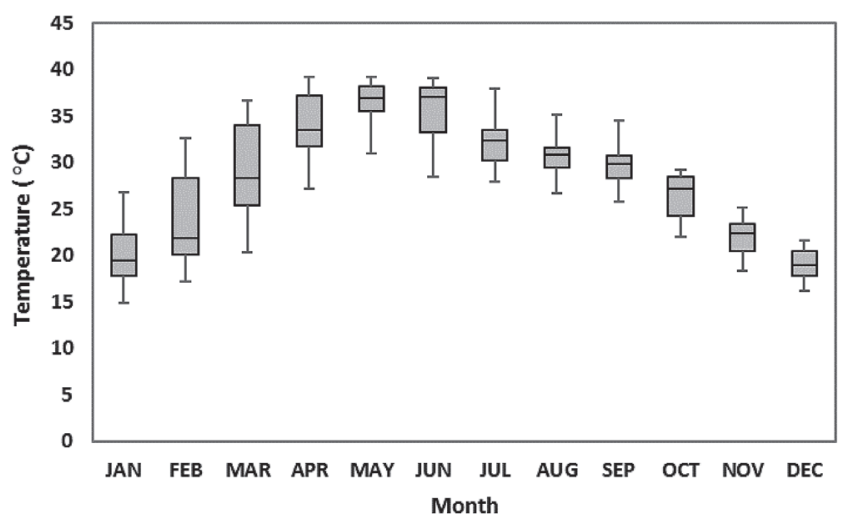

Fig. 3. Box and Whisker plot of the monthly maximum temperature $(\mathrm{TMX})\left({ }^{\circ} \mathrm{C}\right)$

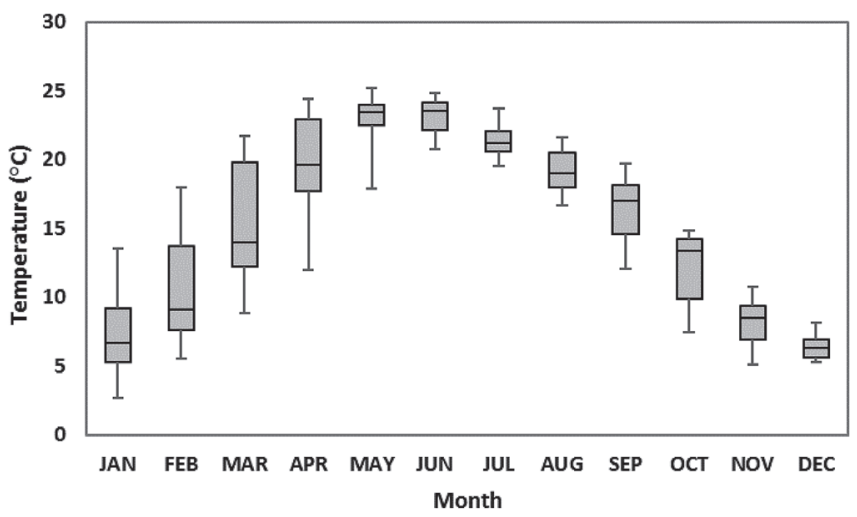

Fig. 4. Box and Whisker plot of the monthly minimum temperature $(T M N)\left({ }^{\circ} \mathrm{C}\right)$

\subsection{Analysis of Monthly Temperatures}

Figures 3 and 4 show box plots for the monthly maximum (TMX) and minimum temperatures (TMN). The plots reveal the distribution of the monthly maximum and minimum temperatures for the study area. The total monthly TMX and TMN were obtained by taking the average values of each month for each year. The box length simply gives an indication of the sample's variability, and it can be seen that the variability is more or less the same for all the months as compared to the rainfall.

\subsection{Measures of Variability}

When analyzing the variability of rainfall, we must not overlook its variations in timescales of seasons to decades. The degree to which rainfall amounts vary across an area or over time is an important characteristic of the climate of an area. Common measures of variability, such as the standard deviation, may be interpreted based upon an assumption of an underlying standard normal distribution for the purpose of climate and weather analyses (Banacos, 2011). To analyze the variability of precipitation, a number of measures of variability have been calculated and analyzed.

The variability of precipitation can be expressed both in absolute as well as in relative terms (Hamid et al. 2013). Some of the absolute measures of variability, i.e., the standard deviation (SD), absolute mean deviation (AMD), and mean absolute inter-annual variability (MAIV) are used for analyses of variability. 


$$
\begin{aligned}
& S D=\left[(N-1)^{-1} \sum_{i=1}^{N}(P-\bar{P})^{2}\right]^{\frac{1}{2}} \\
& A M D=(N-1)^{-1} \sum_{i=1}^{N}\left|P_{i}-\bar{P}\right| \\
& M A I V=(N-1)^{-1} \sum_{i=1}^{N}\left|P_{i}-P_{i-1}\right|
\end{aligned}
$$

Here $P$ is the daily precipitation or monthly precipitation, and $\bar{P}$ is the corresponding average term.

$$
\begin{gathered}
C V=\frac{100 S D}{\bar{P}} \\
R V=\frac{100 A M D}{\bar{P}} \\
P I V=\frac{100 M A I V}{\bar{P}}
\end{gathered}
$$

Table 1 shows the absolute measures of variability (SD, AMD and MAIV) for the monthly rainfall data. The highest values of these parameters have been observed for the months of July and August, which are associated with high values of rainfall. The coefficient of variability $(\mathrm{CV})$, relative variability (RV), and percentage interannual variability (PIV) have also been computed, as they are useful measures of variability widely used in hydro-climatological studies (Hamid et al. 2013).

Tab. 1: SD, AMD, MAIV, $C V, R V$, and PIV for the monthly rainfall at Mandi during the period 1981-2010

\begin{tabular}{ccccc}
\hline Month & June & July & August & September \\
\hline SD & 114.84 & 268.73 & 240.82 & 201.44 \\
\hline AMD & 73.91 & 225.01 & 199.99 & 162.04 \\
\hline MAIV & 97.73 & 386.24 & 282.54 & 228.57 \\
\hline CV (\%) & 134.64 & 53.83 & 42.89 & 86.33 \\
\hline RV (\%) & 86.65 & 45.07 & 35.62 & 69.45 \\
\hline PIV (\%) & 114.58 & 77.36 & 50.32 & 97.97 \\
\hline
\end{tabular}

The results of SD, AMD, and MAIV for the seasonal maximum and minimum temperatures respectively are shown in Tables 2 and 3. For the seasonal maximum temperature, the parameters SD, AMD and MAIV have the highest values for May - March. For the monthly minimum temperature, the maximum values of SD and AMD have been observed in the autumn season (September - November).

Tab. 2: $S D, A M D, M A I V, C V, R V$, and PIV for the seasonal maximum temperature (TMX) at Mandi during the period 1981-2010

\begin{tabular}{ccccc}
\hline Month & DJF & MAM & JJA & SON \\
\hline SD & 2.64 & 2.91 & 2.06 & 2.03 \\
\hline AMD & 2.34 & 2.37 & 1.60 & 1.74 \\
\hline MAIV & 2.05 & 2.80 & 2.80 & 1.98 \\
\hline
\end{tabular}

Tab. 3: SD, AMD, MAIV, CV, RV, and PIV for the seasonal minimum temperatures (TMN) at Mandi during the period 1981-2010

\begin{tabular}{ccccc}
\hline Month & DJF & MAM & JJA & SON \\
\hline \hline SD & 2.09 & 2.66 & 1.03 & 1.90 \\
\hline AMD & 1.76 & 2.24 & 0.90 & 1.73 \\
\hline MAIV & 1.30 & 1.78 & 1.43 & 1.42 \\
\hline
\end{tabular}

\subsection{Trend Analysis}

A summary of the trend analysis at Mandi station is shown in Table 4 and Figure 5. An analysis of six variables using the Mann-Kendall test and Sen's slope estimator was conducted. Among these variables, the annual rainfall does not show any trend for which the Kendall test statistic $(Z)$ value comes out to be zero, and the monsoon rainfall shows a positive trend for which the Kendall test statistical $(Z)$ value comes out to be 0.71 , although it was not statistically significant.

Tab. 4: Trend analysis for Mandi Station from 1981-2010

\begin{tabular}{|l|c|c|c|}
\hline & $\begin{array}{c}\text { Mann-Kendall } \\
\text { Trend }\end{array}$ & $\begin{array}{c}\text { Sen's Slope } \\
\text { estimate }\end{array}$ & \\
\hline Variables & Test $(\boldsymbol{Z})$ & $Q$ & Significance \\
\hline Annual rainfall & 0.02 & -1.96 & Not significant \\
\hline Monsoon rainfall & 0.71 & 12.18 & Not significant \\
\hline Annual TMX & 1.95 & 0.037 & $*$ \\
\hline Monsoon TMX & -1.03 & -0.033 & Not significant \\
\hline Annual TMN & 1.96 & 0.029 & $*$ \\
\hline Monsoon TMN & -1.18 & -0.021 & Not significant \\
\hline \\
$* 0.05$ level of significance; $* * 0.01$ level of significance; \\
$* * * 001$ level of significance
\end{tabular}

For the whole of India, no significant trend was detected for the annual, seasonal, or monthly rainfall (Kumar et al. 2010). The annual and monsoonal precipitation have an equal number of increasing and decreasing trends, although the increasing trends were stronger (Sharif et al. 2013). Both the annual maximum temperature (TMX) and the annual minimum temperature (TMN) show a positive increasing trend with a test statistic $(Z)$ value equal to 1.95 and 1.96 respectively for the $95 \%$ significance level. Bhutiyani et al. (2007) also found an increasing trend in the maximum, minimum, mean, and diurnal temperature range over the northwestern Himalayan region during the $20^{\text {th }}$ century. The maximum and minimum monsoon temperatures show decreasing trends with the Kendall test statistic $(Z)$ values of -1.03 and -1.18 respectively, although they are statistically not significant. Arora et al. (2005) also found that there is a rising trend in most cases, except for temperatures for the mean pre-monsoon, mean monsoon, pre-monsoon mean minimum, and monsoon mean minimum. Kothyari et al. (1997) found a decreasing trend in rainfall magnitude and an increasing trend in the annual maximum temperature in the Ganga Basin in India. The results clearly show the changing patterns of all the parameters. 

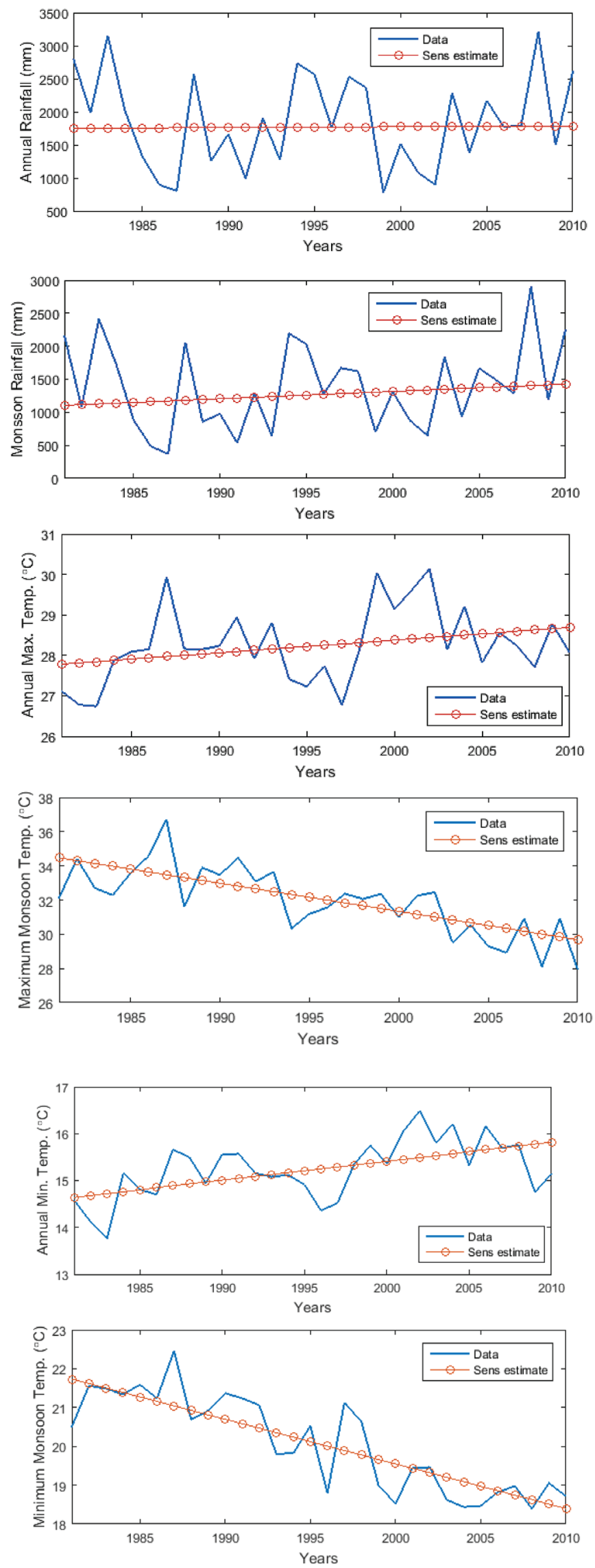

Fig. 5 Plots of annual and monsoon rainfall ( $\mathrm{mm}$ ) and annual average monsoon, minimum and maximum temperature $\left({ }^{\circ} \mathrm{C}\right)$ at Mandi Station

\section{CONCLUSION}

The present study analyzed the hydro-meteorological data for the Mandi station in Himachal Pradesh, India. The analysis of the time series was carried out using a modified Mann-Kendall nonparametric test and Sen's slope estimator, which are widely-used tests for conducting trend analyses of hydro-meteorological data. The variability characteristics of the monthly rainfall, annual maximum temperature (TMX), and annual minimum temperature (TMN) are presented using box and whisker plots. The plots show the relatively maximum amount of rainfall in July and August, while in the case of TMX and TMN, the variability is more or less the same for all the months when compared to the rainfall. A total of six variables were analyzed for trends. The results of the analyses indicate that the annual TMX and TMN for the 1981-2010 periods have shown an increasing trend at a 95\% confidence level, whereas the monsoon TMX and TMN have shown a decreasing trend, although it is not statistically significant. The annual rainfall does not show any trends whereas the monsoonal rainfall has shown increasing trends, although they are not statistically significant. The results clearly indicate that changes are occurring in the temperature and precipitation patterns in the study area. The results of the study also reveal that there are signs of warming in the data analyzed for this research. A more detailed analysis is essential using Indian Meteorological Department (IMD) observed rainfall data for longer periods to confirm or reject the presence of linkages between the changes in the patterns of rainfall and the temperature and climate indices. However, the limitations of this research work are that a period of 30 years (1981-2010) may be regarded as too short of a duration for the determination of any trends. 


\section{REFERENCES}

Anderson, R.L. (1941) Distribution of the serial correlation coefficients. Ann. Math. Stat. Vol. 8, No. 1, 1-13.

Arora, M., Goel, N. K. and Singh, P. (2005) Evaluation of temperature trends over India. Hydrol. Sci. J., Vol. 50, 81-93.

Babar, S.F. and Ramesh, H. (2013) Analysis of south west monsoon rainfall trend using statistical techniques over Nethravathi basin. International Journal of Advanced Technology in Civil Engineering, ISSN: $2231-5721$, Vol. 2, No. 1.

Banacos, Peter C. (2011) Box and Whisker Plots for Local Climate Datasets: Interpretation and Creation using Excel 2007/2010. Eastern Region Technical Attachment No. 2011-01.

Bhutiyani, M.R., Kale, V.S. and Pawar, N.J., (2007) Long-term trends in maximum, minimum and mean annual air temperatures across the Northwestern Himalaya during the twentieth century. Climatic Change, Vol. 85, 159-177.

Burn, D. H. and Sharif, M. (2010) Detection of trends in hydrological extremes for Canadian Watersheds. Hydrological processes, Doi:10.1002/hyp.7625.

Chen, H. S., Guo, H., Xu, Chong-yu., and Singh, Vijay P. (2007) Historical temporal trends of hydro-climatic variables and runoff response to climate variability and their relevance in water resource management in the Hanjiang basin. Journal of Hydrology, Vol. 344, 171- 184

Duhan, D. and Pandey, A. (2013) Statistical analysis of long term spatial and temporal trends of precipitation during 1901-2002 at Madhya Pradesh, India. Atmospheric Research, Vol. 122, 136149.

Duwal, S. (2011) Climatic Data Trend Analysis and Modeling for Water Resource Management in Peloponnese. Greece. Master's thesis Physical Geography and Quaternary Geology, Stockholm University.

Fowler, H.J. and Archer, D. R. (2005) Conflicting signals of climate change in the Upper Indus Basin. Journal of Climate, Vol. 19, 4276- 4293 .

Gemmer, M., Becker, S. and Jiang, T. (2003) Detection and visualization of climate trends in China. Nanjing Institute of Geography and Limnology, Chinese Academy of Science (CAS), Nanjing.

Guhathakurta, P., Sreejith, O. P. and Menon, P. A. (2011) Impact of climate change on extreme rainfall events and flood risk in India. J. Earth Syst. Sci. Indian Academy of Sciences, Vol. 120, No. 3, 359-373.

Hamed, K. H. and Rao A. R. (1998) A modified Mann-Kendall trend test for autocorrelated data. Journal of Hydrology, Vol. 204, 182196.

Hamed, K.H. (2009) Enhancing the effectiveness of pre whitening in trend analysis of hydrologic data. Journal of Hydrology. Vol. $368,143-155$.

Hamid, A.T., Sharif, M. and Ahmed M. L. (2013) Evaluation of trends in meteorological data of Delhi. Special Issue of International Journal of Sustainable Development and Green Economics (IJSDGE), ISSN No. 2315-4721, Vol. 2, No. 1- 2.
Helsel, Dennis R. (1987) Advantages of nonparametric procedures for analysis of water quality data. Hydrological Sciences - Journal - des Sciences Hydrologiques, 32, 2.

Helsel, D. R. and Hirsch, R. M. (1992) Statistical methods in water resources. Elsevier, Amsterdam, 522 pp.

Hingane, L. S., Rupa Kumar, K. and Ramana Murty, V. B. (1985) Long-term trends of surface air temperature in India. Journal of Climatology, 5, 521-528.

Hirsch, R. M., Slack, J. R., and Smith, R. A. (1982) Techniques of trend analysis for monthly water quality data. Water Resources Research, Vol. 18, No. 1, 107-121.

Husain, A. and Hamid, A. T. (2012) Climate Change Impact on Hydro-meteorological Variables: A Review. International Journal of Emerging Technology and Advanced Engineering, Vol. 2, No. 9.

IPCC 2007 Climate change (2007): Climate change impacts, adaptation and vulnerability. Working Group II contribution to the Intergovernmental Panel on Climate Change, Fourth Assessment Report, Summary for policymakers, 23.

Jain, S.K. and Kumar, V. (2012) Trend analysis of rainfall and temperature data for India. Current Science, Vol. 102, 37-42.

Jiang, T., Chen, Xu, Y.D., Yu, C., Xi, C. and Singh, V.P. (2007) Comparison of hydrological impacts of climate change simulated by six hydrological models in the Dongjiang basin, south China. J Hydrology, Vol. 336, 316-333.

Kendall, M.G. (1975) Rank Correlation Methods, $4^{\text {th }}$ edition. Charles Griffin, London, U.K.

Khaliq, M. N., Ouarda, T. B. M. J., Gachon, P., Sushama, L., and St-Hilaire, A. (2009) Identification of hydrological trends in the presence of serial and cross correlations: A review of selected methods and their application to annual flow regimes of Canadian rivers. Journal of Hydrology, Vol. 368, 117-130.

Khattak, M. Shahzad., Babell, M. S. and Sharif, M. (2011) $H y$ dro-meteorological trends in the upper Indus River basin in Pakistan. Inter-Research, Vol. 46, 103-119, 2011 doi: 10.3354/ cr00957.

Kothyari, U. C., Singh, V. P. and Aravamuthan, V. (1997) An Investigation of Changes in Rainfall and Temperature Regimes of the Ganga Basin in India. Water Resources Management, Vol. 11, No. 17.

Kumar, V., Jain, S.K. and Singh, Y. 2010 Analysis of long-term rainfall trends in India. Hydrological Sciences Journal - Journal des Sciences Hydrologiques, Vol. 55, No. 4.

MAKESENS 1 (2002) User's manual.

Mann, H. B. (1945) Non-parametric test against trend. Econometrica, Vol. 13, 245-259.

Marco, G., Stefan, B. and Tong. J. 2003 Detection and Visualization of Climate Trends in China. No. 15, Giessen, Nanjing Institute of Geography and Limnology, Chinese Academy of Science (CAS).

Önöz, B. and Bayazit, M. (2012) Block bootstrap for Mann-Kendall trend test of serially dependent data. Hydrol. Process, Vol. $26,3552-3560$. 
Ramachandra. T. V., Gautham K. and Rishab J. (2012) Solar Potential in the Himalayan Landscape. International Scholarly Research Network, ISRN Renewable Energy, Vol. 13.

Rao, P. G. S., Murty, M.K. and Joshi, U.R. (2005) Climate change over India as revealed by critical extreme temperature analysis. Mausam, Vol. 56, 601-608.

Sen, P. K. (1968) Estimates of the regression coefficient based on Kendall's tau. Journal of American Statistical Association, Vol. 39, 1379-1389.

Sharif, M., and Wazir, K. S. (2013) Precipitation trends in northern India. Advances in Engineering and Technology Convergence, Bangkok, Thailand, ISBN no: 978-93-82208-89-1.

Sharif, M., Burn, D. and Hussain, A. (2010) Climate Change Impacts on Extreme Flow Measures in Satluj River Basin in India. World Environmental and Water Resources Congress 2010:46, Challenges of Change.

Singh, O., Arya, P. and Chaudhary, B.S. (2013) On rising temperature trends at Dehradun in Doon valley of Uttarakhand, India. J. Earth Syst. Sci., Indian Academy of Sciences, Vol. 122, 613-622.

Singh, P., Kumar, V., Thomas, T. and Arora, M. (2008) Basin wide assessment of temperature trends in northwest and central India. Hydrological Science Journal, Vol. 53, 421-433.
Sinha Ray, K. C., Mukhopadhya, R. K. and Chowdhary, S.K. (1997) Trend in maximum and minimum temperature and sea level pressure over India. Intromet, IIT Delhi, HauzKhas, New Delhi.

Sinha Ray, K. C. and Srivastava, A. K. (2000) Is there any change in extreme events like heavy rainfall? Current Science, Vol. 79, $155-158$.

Van, B. G. and Hughes, J. P. (1984) Nonparametric Tests for Trend in Water Quality. Water resources research, Vol. 20, 127-136.

$\mathbf{X u}, \mathbf{K}$. and Xu, H. (2010) Temporal trend of precipitation and runoff in major Chinese rivers since 1951. Global and Planetary Change, Vol. 73, 219-232.

Yue, S., Pilon, P., and Cavadias, G. (2002) Power of the Mann-Kendall and Spearman's rho tests for detecting monotonic trends in hydrological series. J. Hydrology, Vol. 259, 254-271.

Zhang, Q., Liu, C., Xu, C.Y., Xu, Y.P. and Jiang, T. (2006) $O b$ served trends of water level and streamflow during past 100 years in the Yangtze River basin. China. J. Hydrology, Vol. 324, No. $1-4,255-265$. 